\title{
Intestinal morphology of Thai pangas (Pangasianodon hypophthalmus) under probiotic supplemented conditions
}

\author{
RASHIDUL HASSAN, FAHMIDA AKTER, MD. ASEK UDDIN, TAMANNA \\ TABASSUM, MD. ABDULLAH AL MAHAMUD, GIAS UDDIN AHMED* AND \\ TANVIR RAHMAN \\ Department of Aquaculture, Bangladesh Agricultural University, Mymensingh 2202, Bangladesh \\ *Email: giasa50@gmail.com
}

\begin{abstract}
The present study was conducted to evaluate the effects of probiotic supplementation on the intestinal morphology of Thai pangasius (Pangasianodonhypophthalmus). The experiment was conducted in 15 earthen ponds of $0.75 \mathrm{dec}$. each. Each pond contained 600 fingerlings/decimal $(5.69 \pm 1.23 \mathrm{~g})$ and the feeding trial was performed for 90 days. Commercially available gut nutrient additive, Mutagen and $\mathrm{pH}$ FIXER (water additive probiotic) were used in the experiment. Five treatments were conducted each having three replicates.Treatment $1\left(\mathrm{~T}_{1}\right)$ was provided with gut probiotics, treatment $2\left(\mathrm{~T}_{2}\right)$ with water probiotics, Treatment $3\left(\mathrm{~T}_{3}\right)$ with $50 \%$ gut probiotic and $50 \%$ water probiotic; Treatment $4\left(\mathrm{~T}_{4}\right)$ with prebiotic (yeast and rice starch) and 50\% gut and 50\% water probiotic.Treatment $5\left(\mathrm{~T}_{5}\right)$ was designed as control. Fishes were fed twice a day at the rate of $10-5 \%$ of body weight. Samplings were carried out fortnightly where gut samples were collected for histology and water quality parameters were recorded. All water quality parameters were found to be favorable for fish culture. Histological analysis of the gastrointestinal tract revealed that fold length, width and enterocyte height were significantly larger $(p<0.05)$ in fish of $\mathrm{T}_{3}$ and $\mathrm{T}_{4}$ compared to those of $T_{1}, T_{2}, T_{5}$. Thus, probiotic supplementation can improve the intestinal morphology of Thai pangasius which may increase the nutrient absorption in fish and thereby increase the digestion capacity.
\end{abstract}

Keywords: Pangasianodonhypophthalmus, Probiotics, Prebiotics.

\section{Introduction}

One of the fastest-growing types of aquaculture of the world is Pangasius farming. Striped catfish (Pangasiandon hypophthalmus) is considered as one of the most successful aquaculture species in Bangladesh due to its relative ease in culture, high-market demand and suitability to local climate conditions (Rahman et al. 2004). High disease resistance, faster growth, high stocking density with greater production rates (up to $120 \mathrm{fish} / \mathrm{m}^{2}$, average 40 tones/ha; UNFAO 2010) make it an ideal cultivar for increasing aquaculture production in Bangladesh. In 1990, the ministry of Fishery and Livestock imported this faster-growing catfish from Thailand. Prebiotics and probiotics constitute a different approach to preventing diseases in cultured fish and shellfish and have shown several beneficial impacts, including improved growth, survival, immunological responses, increased area of intestinal absorption, and enhanced general well-being of the host (Mayra et al. 2018).

The word probiotic was first introduced by Lilly and Stillwell (1965) to describe "substances secreted by one microorganism that stimulate the growth of another." However, the authors defined it as viable microorganisms with a beneficial effect on the host. Akhter et al. (2015) indicated that probiotics are microorganisms that are administered orally in a sufficient amount to alter the microbiota (by implantation or colonization) of the specific host 
and lead to benefits for the host's health. On the other hand, Banerjee et al. (2017) defined probiotics as live microorganisms that confer beneficial effects to the host (improves immunity, helps digestion, protects against pathogens, improves water quality, and promotes growth and reproduction), and can be used as an alternative to antibiotics. To ensure safe aquaculture, the use of probiotics is now transforming the approach in health care strategy from human to fish. Introducing probiotics as an alternative strategy to chemotherapy in Pangasiusculture may significantly improve nutrient digestion, enrich the aquatic environment and ensure safe food.

The intestine is one of the most important parts in the fish body which could relate to changes in the nutrient absorption of fish (Purushothaman et al. 2016). Intestinal villi height is one of the most important parts which could determine the efficacy of the nutrient absorption of fishes. Hence, the objective of the study was to evaluate the effects of probiotics on intestinal morphology such as fold length, fold width and enterocyte height of gut villi of $P$. hypophthalmus.

\section{Materials and Methods}

Study area and duration: The experiment was conducted in 15 earthen ponds situated on the south side of the Faculty of Fisheries, Bangladesh Agricultural University, Mymensingh for 90 days. Lime and salt were applied to all the ponds at a dose of $1 \mathrm{~kg} / \mathrm{decimal}$.

Preparation of probiotic supplemented feed: Two commercially available probiotics viz., Mutagen, as gut probiotic (high-quality minerals with multivitamins and amino acid and immune enhancer, Thailand) and $\mathrm{pH}$ FIXER (a concentrated strain of beneficial Bacillus bacteria, maintains optimum pond water quality, India) as water probiotic were selected. Yeast as prebiotic which was collected locally. According to the experimental design, the feed was prepared to mix with probiotic supplementation, dried for an overnight inside the room using a fan. After drying feeds were kept in airtight plastic bags, stored in the laboratory at room temperature.

Experimental design: Fifteen ponds with an area of 0.75 decimal each and 1-meter depth were used. The experiment was designed with five treatments each having three replications. Diet for treatment $1\left(\mathrm{~T}_{1}\right)$ was prepared with mutagen $\left(15 \mathrm{~g} / \mathrm{kg}\right.$ feed). Treatment $2\left(\mathrm{~T}_{2}\right)$ was prepared with pH FIXER (13 g/pond). Treatment $\left(\mathrm{T}_{3}\right)$ with half of manufacturer's recommended gut probiotic and half of manufacturer's recommended water probiotic. Treatment $4\left(\mathrm{~T}_{4}\right)$ contained diet with half of mutagen, half of pH FIXER and 3\% yeast mixed with rice starch of total feed weight. The fifth treatment ( $\left.\mathrm{T}_{5}\right)$ was a control, without any probiotics. Healthy pangasius $(P$. hypophthalmus) fingerling $(5.69 \pm 1.23 \mathrm{~g})$, were collected from Al-Amin Hatchery, located near the Bangladesh Fisheries Research Institute, Mymensingh. Fish was stocked at a density of of 600 fingerlings/decimal.

Feeding experiment and sampling of fish: Commercial floating feed (Mega feed) was used directly for control treatment and probiotic and prebiotic mixed feed were used for other treatments twice a day at 9 am and $5 \mathrm{pm}$ at the rate of 10-5\% of body weight. Sampling was carried out fortnightly, using cast net and body weight of the sampled fish was measured carefully using an electric balance. 
Monitoring of water quality parameters: Water quality parameters viz., water temperature $\left({ }^{\circ} \mathrm{C}\right), \mathrm{pH}$, dissolved oxygen (DO) $(\mathrm{mg} / \mathrm{L})$ and free ammonia $\left(\mathrm{NH}_{3}\right)$ were monitored fortnightly.

Histological examination: Fish gut samples from 5 fishes of each treatment were collected fortnightly during the experiment. The samples were fixed with $10 \%$ buffered formalin and then processed for dehydration, clearing and infiltration gradually in an Automatic Tissue Processor (SHANDON, CITADEL 1000). The samples were then embedded by melted wax and sectioned by a microtome at a thickness of $7 \mu \mathrm{m}$. The slides were then dried on a hot plate at a temperature of $37^{\circ} \mathrm{C}$ for $1 \mathrm{~h}$. After that, the specimen slides were stained with routine hematoxylin and eosin stains and then mounted with Canada balsam and coverslips. Finally, photographs were taken by a photomicroscope (Electronic Carl Zeiss microscope).

\section{Results}

Observations of fold length (FL), fold width (FW) and enterocyte height (EH) of gut villi: Based on the observations and measurements, the histological section of intestinal morphology like villi height (fold length as FL), villi width (fold width as FW), villi enterocyte height (EH) of the fish gut were shown in Figs. 1, 2 and 3. The highest fold length (FL,75.540 $\pm 0.35 \mu \mathrm{m}$ ), width (FW, $51.657 \pm 0.12 \mu \mathrm{m}$ ), enterocyte height $(\mathrm{EH}, 23.584 \pm 0.07 \mu \mathrm{m})$ were observed in $\mathrm{T}_{3}$ compared with all other treatments. On the other hand, the lowest fold length (FL), width (FW), enterocyte height $(\mathrm{EH})$ were observed in $\mathrm{T}_{5}$ (control). Fishes of $\mathrm{T}_{4}$ also showed larger fold length (FL), width (FW), enterocyte height (EH) compared to $T_{1}, T_{2}$ and $T_{5}$. Fishes of $T_{2}$ also showed better fold length (FL), width (FW), enterocyte height (EH) compared to $\mathrm{T}_{1}$ and $\mathrm{T}_{5}$.

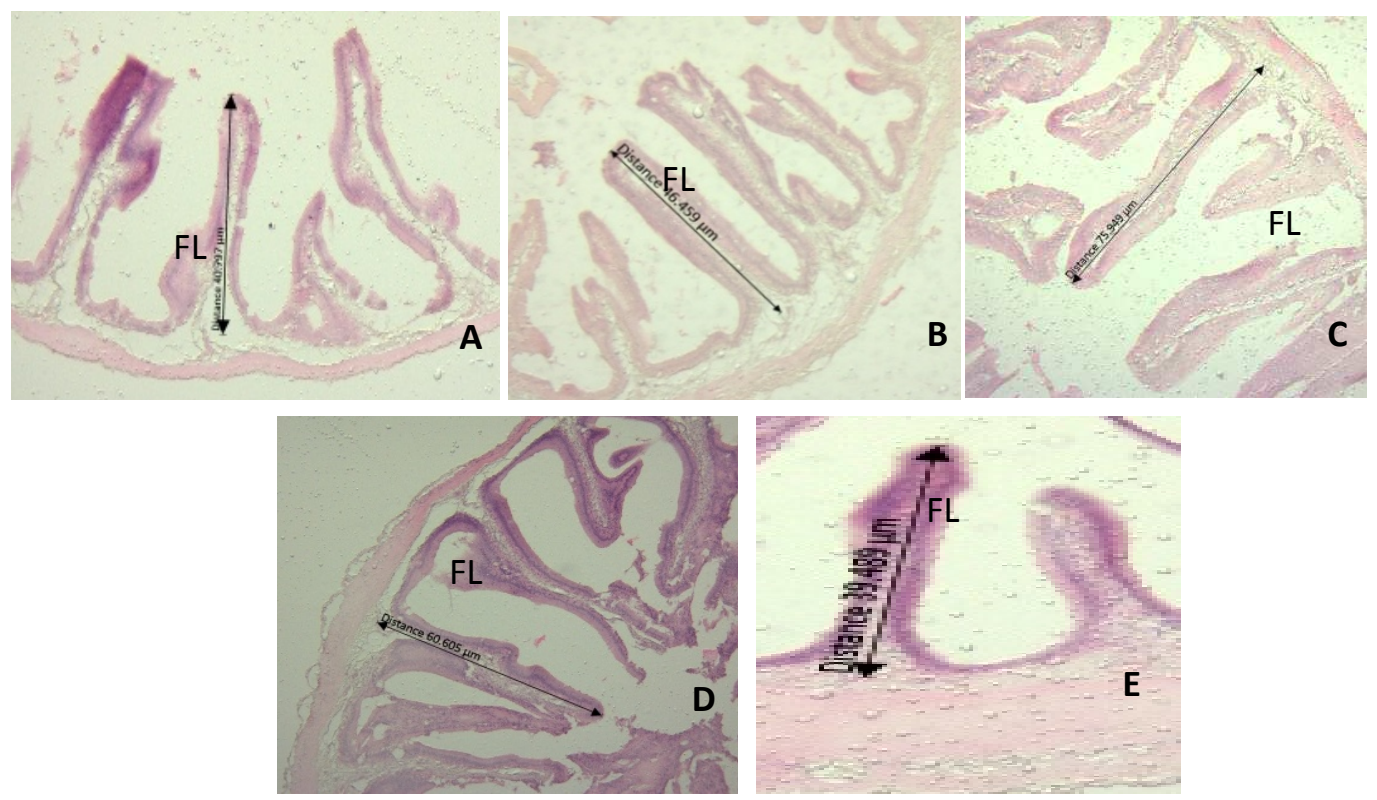

Fig. 1. Small intestine of $P$. hypophthalmus at the end of feeding trials, having differences in the intestinal villi height (VH) (Fold length). A. T1; B. T2; C. T3; D. T4; E. T5. H \& E ×120. 


\section{INTESTINAL MORPHOLOGY OF THAI PANGAS}

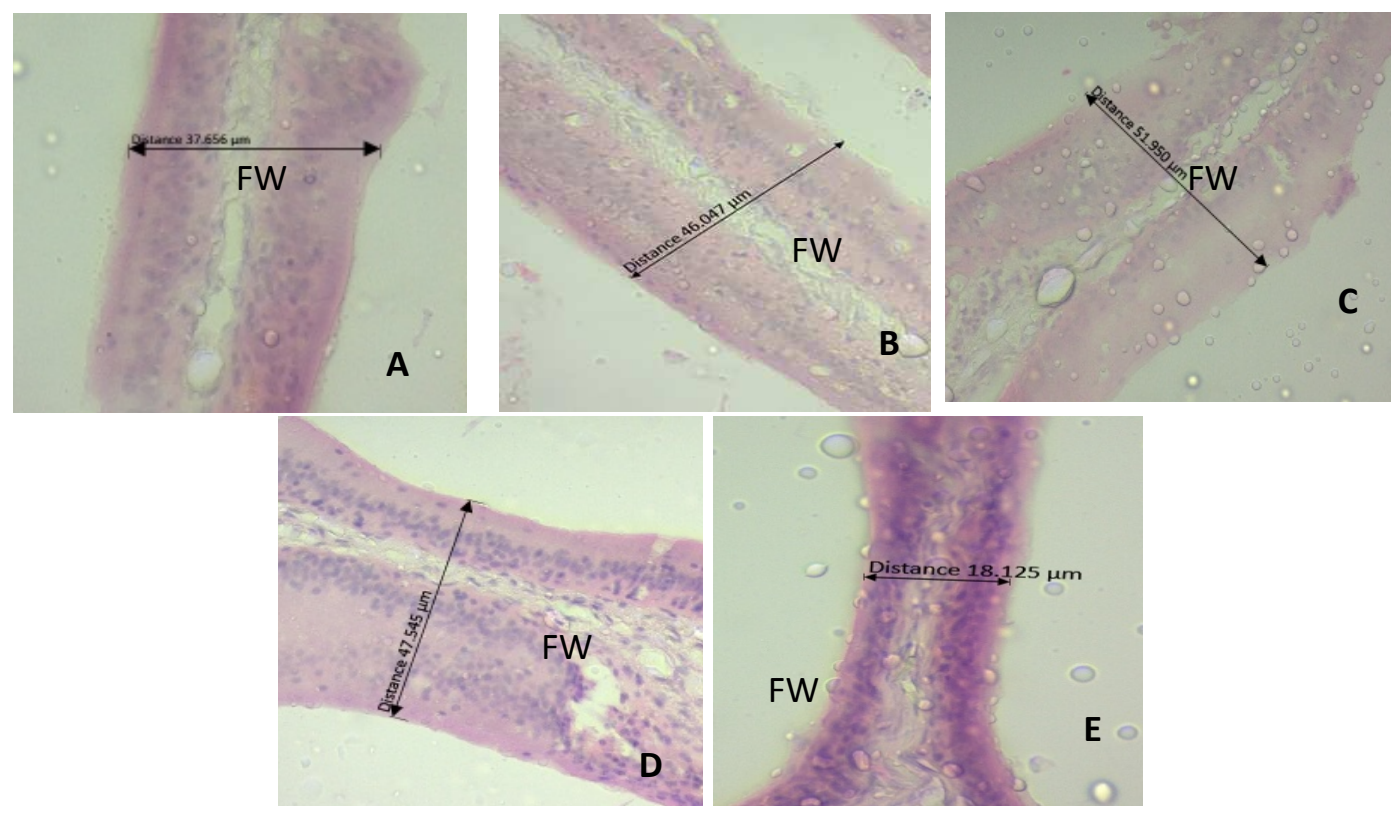

Fig. 2. Histological section of the small intestine of $P$. hypophthalmus at the end of the experiment with differences in intestinal villi width (Fold width). A. T 1 ; B. T2; C.

$\mathrm{T}_{3}$; D. T4; E. T5 (control). H \& E ×430.
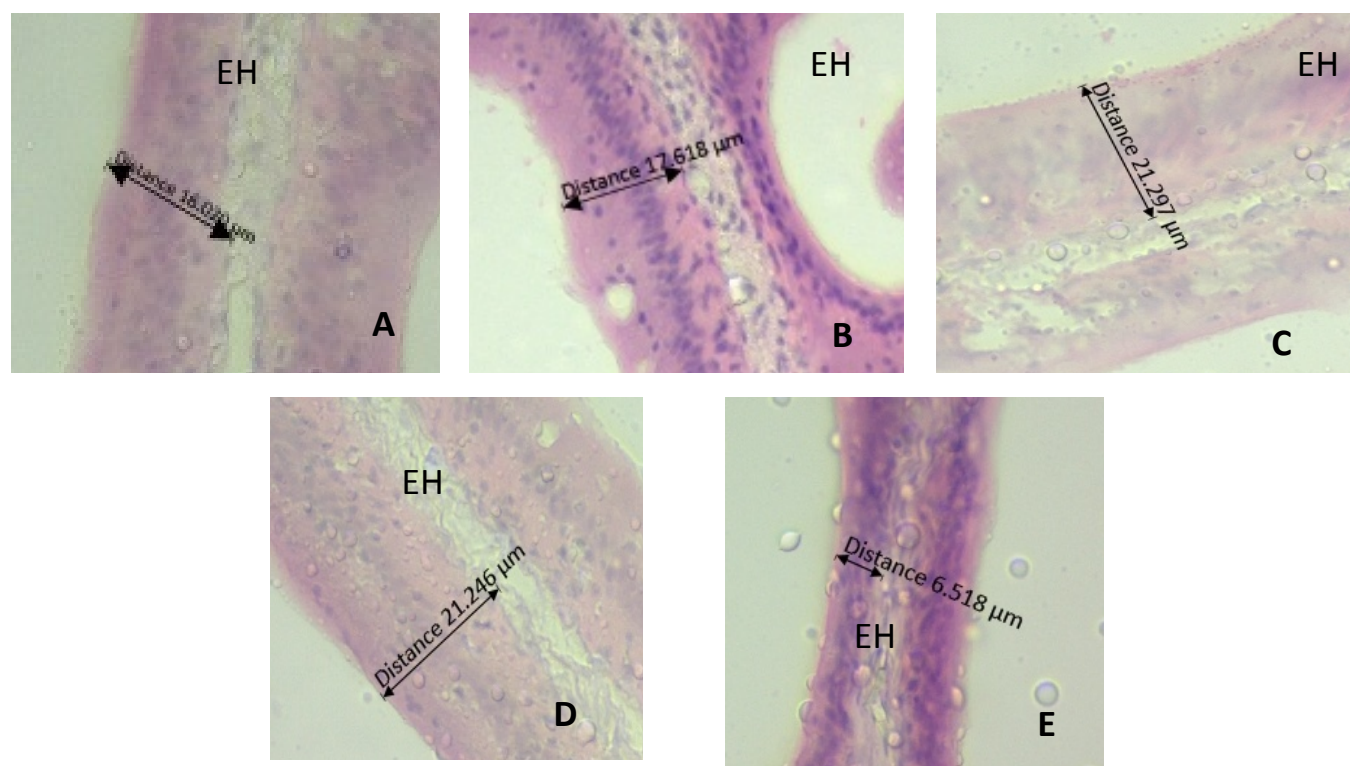

Fig. 3. Cross-section of small intestine of $P$. hypophthalmus at end of feeding trials, showing differences in intestinal villi enterocyte height (EH). A. T1; B. T2 $;$ C. T3 $;$ D. T4; E. T5 (control). H \& E $\times 430$. 
RASHIDUL HASSAN et al.

Comparison of intestinal villi height (fold length), width (fold width), enterocyte height: The highest fold length, width and enterocyte height of $P$. hypophthalmus at the start, middle and end of the experiment was observed in $T_{3}$ compared to other treatments and the lowest was observed in $\mathrm{T}_{5}$ (Table I). At the begining of the experiment, fishes of $\mathrm{T}_{4}$ exhibited larger fold length (FL), width (FW), enterocyte height (EH) in comparison with $\mathrm{T}_{1}, \mathrm{~T}_{2}$ and $\mathrm{T}_{5}$ and fish of $\mathrm{T}_{1}$ provided increased fold width (FW), enterocyte height (EH) compared with $\mathrm{T}_{2}$ and $\mathrm{T}_{5}$ (Table I). At the middle of the experiment, $T_{4}$ provided higher fold length and width compared with $T_{1}, T_{2}$ and $T_{5}$, whereas $T_{2}$ showed increased enterocyte height than $T_{1}, T_{4}$ and $T_{5}$ and $T_{4}$ had larger fold width than $\mathrm{T}_{3}$ (Table I). During termination of the experiment, the highest fold length, width and enterocyte height were recorded in $\mathrm{T}_{3}$; however, $\mathrm{T}_{4}$ had larger fold length, width and enterocyte height compared with $\mathrm{T}_{1}, \mathrm{~T}_{2}$ and $\mathrm{T}_{5}$; whereas, $\mathrm{T}_{2}$ had larger fold length, width and enterocyte height compared with $\mathrm{T}_{1}$ and $\mathrm{T}_{5}$ (Table $\mathrm{I}$ ).

Table I. Measurement of intestinal villi height (fold length), width (fold width), enterocyte height of $P$. hypophthalmus during 90 days of feeding trial(mean \pm S.E)

\begin{tabular}{lccccc}
\hline $\begin{array}{l}\text { Experimental } \\
\text { period }\end{array}$ & Treatments & $\begin{array}{c}\text { Fold length } \\
(\mathrm{FL}) \mu \mathrm{m}\end{array}$ & $\begin{array}{c}\text { Fold width } \\
(\mathrm{FW}) \mu \mathrm{m}\end{array}$ & $\begin{array}{c}\text { Enterocyte } \\
\text { height }(\mathrm{EH}) \mu \mathrm{m}\end{array}$ & $\begin{array}{c}\text { Lumen width } \\
(\mathrm{FW}-2 * \mathrm{EH}) \\
\mu \mathrm{m}\end{array}$ \\
\hline \multirow{4}{*}{ 1-30 days } & $\mathrm{T}_{1}$ & $24.978 \pm 0.14$ & $27.509 \pm 0.24$ & $12.673 \pm 0.04$ & $2.120 \pm 0.07$ \\
& $\mathrm{~T}_{2}$ & $30.903 \pm 0.23$ & $26.339 \pm 0.28$ & $11.106 \pm 0.002$ & $4.530 \pm 0.04$ \\
& $\mathrm{~T}_{3}$ & $43.351 \pm 0.43$ & $30.531 \pm 0.31$ & $13.700 \pm 0.104$ & $3.164 \pm 0.005$ \\
& $\mathrm{~T}_{4}$ & $34.189 \pm 0.10$ & $34.120 \pm 0.05$ & $15.107 \pm 0.002$ & $4.026 \pm 0.004$ \\
& $\mathrm{~T}_{5}$ & $18.069 \pm 0.29$ & $13.048 \pm 0.29$ & $5.310 \pm 0.04$ & $2.540 \pm 0.04$ \\
\hline \multirow{3}{*}{$31-60$ days } & $\mathrm{T}_{1}$ & $29.469 \pm 0.26$ & $27.997 \pm 0.07$ & $13.776 \pm 0.104$ & $0.183 \pm 0.007$ \\
& $\mathrm{~T}_{2}$ & $39.934 \pm 0.21$ & $40.332 \pm 0.12$ & $19.610 \pm 0.04$ & $0.808 \pm 0.004$ \\
& $\mathrm{~T}_{3}$ & $53.986 \pm 0.19$ & $39.615 \pm 0.16$ & $19.584 \pm 0.17$ & $1.116 \pm 0.004$ \\
& $\mathrm{~T}_{4}$ & $52.875 \pm 0.28$ & $41.339 \pm 0.05$ & $18.566 \pm 0.04$ & $4.232 \pm 0.005$ \\
& $\mathrm{~T}_{5}$ & $30.025 \pm 0.31$ & $15.332 \pm 0.14$ & $7.053 \pm 0.007$ & $1.372 \pm 0.057$ \\
\hline \multirow{6}{*}{$61-90$ days } & $\mathrm{T}_{1}$ & $40.551 \pm 0.24$ & $37.474 \pm 0.24$ & $18.117 \pm 0.09$ & $1.543 \pm 0.038$ \\
& $\mathrm{~T}_{2}$ & $46.228 \pm 0.10$ & $46.655 \pm 0.14$ & $21.341 \pm 0.05$ & $4.424 \pm 0.033$ \\
& $\mathrm{~T}_{3}$ & $75.540 \pm 0.35$ & $51.657 \pm 0.12$ & $23.584 \pm 0.12$ & $4.654 \pm 0.139$ \\
& $\mathrm{~T}_{4}$ & $60.237 \pm 0.16$ & $47.561 \pm 0.02$ & $23.477 \pm 0.04$ & $0.697 \pm 0.023$ \\
& $\mathrm{~T}_{5}$ & $39.220 \pm 0.23$ & $18.225 \pm 0.05$ & $6.499 \pm 0.023$ & $5.055 \pm 0.014$ \\
\hline
\end{tabular}

Water quality parameters:Optimum water quality parameters are the key factors for survival and functioning of beneficial organisms of probiotic. In the present study, the water temperature varied from $23.13 \pm 0.06$ to $32.2 \pm 0.02^{\circ} \mathrm{C}$ where dissolve oxygen (DO) concentration in water varied from $2.16 \pm 0.04$ to $7.33 \pm 0.04 \mathrm{mg} / \mathrm{l}$. During the study period, $\mathrm{pH}$ values varied from $7.13 \pm 0.02$ to $8.36 \pm 0.09$. Unionized ammonia $\left(\mathrm{NH}_{3}\right)$ is toxic to fish, while the ammonium ion $\left(\mathrm{NH}_{4+}\right)$ is not toxic. Free ammonia $\left(\mathrm{NH}_{3}\right)$ concentrations were varied from $0.02 \pm 0.001$ to $0.04 \pm 0.001 \mathrm{mg} / \mathrm{L}$ (Table II). 
INTESTINAL MORPHOLOGY OF THAI PANGAS

Table II. Summary of water quality parameters observed during the experimental period

\begin{tabular}{lc}
\hline Parameters & Value range $(($ mean $\pm \mathrm{S} . \mathrm{E})$ \\
\hline Temperature $\left({ }^{0} \mathrm{C}\right)$ & $23.13 \pm 0.06$ to $32.2 \pm 0.02$ \\
$\mathrm{pH}$ & $7.13 \pm 0.02$ to $8.36 \pm 0.09$ \\
Dissolved Oxygen $(\mathrm{mg} / \mathrm{l})$ & $2.16 \pm 0.04$ to $7.33 \pm 0.04$ \\
Ammonia $\left(\mathrm{NH}_{3}\right)(\mathrm{mg} / \mathrm{l})$ & $0.02 \pm 0.001$ to $0.04 \pm 0.001$ \\
\hline
\end{tabular}

\section{Discussion}

The present investigation was aimed to observe the effects of probiotics on intestine of Pangasianodon hypophthalmus specially its fold length, fold width and enterocyte height which were differed significantly under various probiotic supplementations.

Probiotic is a microbial supplement with living microorganism with beneficial effects to the host, by modifying its microbial community associated with the host or its farming environment, ensuring better use of artificial food and its nutritional value by improving the host's response to diseases and improving the quality of the farming environment (Verschuere et al. 2000). Water quality parameters are one of the most important factors for successful aquaculture and the beneficial effects of probiotic in water quality improvement has proven in aquaculture. In the present experiment water temperature were varied from $23.13 \pm 0.06$ to $32.2 \pm 0.02^{\circ} \mathrm{C}$ during the study period. Kohinoor et al. (2012) and Haque (2014) measured water temperatures in ponds varied from $27.90-27.49^{\circ} \mathrm{C}$ and 24 to $32.8^{\circ} \mathrm{C}$ respectively, which were more or less similar to the values of present study. In the present study, DO concentration in water varied from $2.16 \pm 0.04$ to $7.33 \pm 0.04 \mathrm{mg} / \mathrm{l}$. Growth and feeding decreases at $1-5 \mathrm{mg} / \mathrm{L}$ of DO and growth and production is optimum at more than $5 \mathrm{mg} / \mathrm{L}$ (Jhingran 1988). According to Rahman (2004), dissolve oxygen content of a productive pond should be $5.0 \mathrm{ppm}$ or more. DoF (1996) reported that the range of suitable dissolve oxygen for fish culture would be 5.50 to $6.50 \mathrm{mg} / \mathrm{l}$. So, it could be mentioned that the values of DO concentration observed in the present research were suitable for fish culture. In the present research, the range of $\mathrm{pH}$ varied from $7.13 \pm 0.02$ to $8.36 \pm 0.09$. Ahmed et al. (1996) found $\mathrm{pH}$ range from 6.5 to 8.5 and Kohinoor et al. (2012) recorded $\mathrm{pH}$ range from 7.08 to 7.15 which is almost similar with the finding of the present investigation. Unionized ammonia $\left(\mathrm{NH}_{3}\right)$ is toxic to fish, while the ammonium ion $\left(\mathrm{NH}^{+}\right)$is not toxic. In the present study free ammonia $\left(\mathrm{NH}_{3}\right)$ concentrations were varied from $0.02 \pm 0.001$ to $0.04 \pm 0.001 \mathrm{mg} / \mathrm{l}$. According to Santhosh and Singh (2007), maximum limit of ammonia concentration for aquatic organisms is $0.1 \mathrm{mg} / \mathrm{l}$ while Bhatnagar and Singh (2010) recommended that ammonia levels of less than $0.2 \mathrm{mg} / 1$ are suitable for pond fishery. According to Jhingran (1988), the concentration of unionized ammonia should not exceed more than $0.025 \mathrm{ppm}$. So, it could be mentioned that the values of ammonia concentration observed in the present research were suitable for fish culture.

In the present experiment after 90 days of feeding the probiotic and prebiotic to Pangasianodon, histological measurements showed that fish fed the prebiotic and probiotic supplemented feeds had significantly larger FL $(60.605 \mu \mathrm{m})$, FW $(47.594 \mu \mathrm{m})$ and EH $(23.543$ $\mu \mathrm{m})$ compared to the treatments with no prebiotic and probiotic $(39.505 \mu \mathrm{m}, 18.329 \mu \mathrm{m}$ and $6.534 \mu \mathrm{m})$. Based on measurement made, fish fed the diet containing $50 \%$ gut probiotic and $50 \%$ water probiotic (T3), showed the largest FL $(75.998 \mu \mathrm{m})$, FW $(51.950 \mu \mathrm{m})$ and $\mathrm{EH}$ 
$(23.744 \mu \mathrm{m})$ followed by fish in $\mathrm{T}_{1}, \mathrm{~T}_{2}, \mathrm{~T}_{4}$ and $\mathrm{T}_{5}$. It is due to fact that more efficient nutrient absorption has occurred when fish fed probiont supplemented feed with probiotic in pond water which resulted to a physically healthy fish.Mayraet al. (2018) mentioned that after 109 days of feeding the probiotic and prebiotic to Totoaba, histological measurements showed that fish fed probiotic supplemented feeds had significantly larger FL $(435.6 \mu \mathrm{m})$ in the proximal segment of the GIT compared to the treatments with no probiotic $(382.3 \mu \mathrm{m})$ and fish fed the diet containing both, probiotic and prebiotic, showed the largest FL $(448.7 \mu \mathrm{m})$. Merrifield et al. (2010) demonstrated that dietary applications of $P$. acidilactici could significantly improve microvilli length in $O$. mykiss proximal intestine compared to the control group. According to Zhou et al. (2010), microvilli height increases in the pyloric caeca, proximal intestine, and mid intestine, but not the distal intestine, when $S$. ocellatus fed diets supplemented with various prebiotics. From the observations of Peredo et al. (2015), it could be mentioned that when $O$. niloticus fed GroBiotic-A at either 1 or $2 \%$ dietary inclusion, histometric measurements of various sections of the GIT showed limited differences, and when fish fed both the basal diet and diet containing $1 \%$ GroBiotic-A had significantly greater fold height in the proximal intestine, when compared to fish fed the diet supplemented with $2 \%$ GroBiotic-A. The authors also observed that fish fed the basal diet exhibited significantly greater microvilli height in the same region when compared to fish fed the diet supplemented with $2 \%$ GroBiotic-A, but not the diet containing $1 \%$ GroBiotic-A. Thus, the highest intestinal villi length, width and enterocyte height showed by fish fed with probiont-supplemented feed and water probiotic in pond water $\left(\mathrm{T}_{3}\right)$. So, it could be mentioned that combined supplementation of gut probiotic and water probiotic provided the highest villi length, width and enterocyte height than those of singular supply of gut or water probiotic or combined supply with prebiotic. This showed the highest nutrient absorption occurred in the fish intestine which can be reflected by better growth performance when compared with other treatments. Fish from $T_{1}, T_{2}, T_{3}, T_{4}$ showed larger fold length, width and enterocyte height than those of $\mathrm{T}_{5}$ (control) which proved that probiotic supplementation can improve the intestinal morphology of Thai pangasius ( $P$. hypophthalmus) which will increase the nutrient absorption of fish. Thereby increase the digestion of fish. That's why health status of Thai pangas ( $P$. hypophthalmus) will be improved in the probiotic and prebiotic supplemented feed treatments. Farmers can use prebiotic and probiotic with fish feeds to obtain healthy gut which ultimately yields healthy fish and increased production.

Acknowledgements: The authors would like to acknowledge the KrishiGobeshona Foundation (KGF) for their financial assistance to carry out the research work.

\section{Literature Cited}

Ahmed, G.U., M.R.I. Sarder and M.G. Kibria, 1996. Culture feasibility of pangas (Pangasius pangasius Ham.) in earthen ponds with different supplement diets. Bangladesh J. Fish.,19(12): $23-27$.

Akhter, N., B. Wu, A.M. Memon, M. Mohsin, 2015. Probiotics and prebiotics associated with aquaculture: A review. Fish Shellfish Immunol., 45(2): 733-741.

Banerjee, G, A. Nandi and A.K. Ray, 2017. Assessment of hemolytic activity, enzyme production and bacteriocin characterization of Bacillus subtilis LR1 isolated from the gastrointestinal tract of fish. Arch. Microbiol., 199(1):115-124. 
Bhatnagar, A and G. Singh, 2010. Culture fisheries in village ponds: a multi-location study in Haryana, India. Agricult. Biol. J. North Am., 1(5): 961-968.

DoF, 1996. Annual Report, Department of Fisheries, Ministry of Fisheries and Livestock, Dhaka, Bangladesh. $81 \mathrm{p}$.

Haque, M., 2014. Optimization of stocking density on growth and production of mono-sex tilapia in a pond, MS Thesis, Department of Aquaculture, BAU, Mymensingh. 51 p.

Jhingran, V.G., 1988. Fish and Fisheries of India. Hindustan Publishing Corporation, Delhi, India.

Kohinoor, A.H.M., M.M. Khan, S. Yeasmine, P. Mandol and M.S. Islam, 2012. Effects of stocking density on growth and production performance of indigenous Stinging catfish, Heteropneustesfossilis (Bloch). Int. J. Agric. Res.Innov. Technol., 2: 9-14.

Lilly, D.M. and R.H. Stillwell, 1965. Probiotics: Growth-promoting factors produced by microorganisms. Science, 147: 747-748.

Mayra, L., S. Filiberto, Y. Fernando and O. L. Adrian, 2018. Effects of commercial dietary prebiotic and probiotic supplements on growth, innate immune responses, and intestinal microbiota and histology of Totoabamacdonaldi. Aquaculture, 491: 239-251.

Merrifield, D.L., G.M. Harper, A, Dimitroglou, E. Ringø and S.J. Davies, 2010. Possible influence of probiotic adhesion to intestinal mucosa on the activity and morphology of rainbow trout (Oncorhynchusmykiss) enterocytes. Aquac. Res., 41: 1268-1272.

Peredoetal, A.M., A. Buentello, D.M. Gatlin and M. Hume, 2015. Evaluation of a dairy yeast prebiotic in the diet of juvenile Nile Tilapia, Oreochromisniloticus. J. World Aquac. Soc., 46: 92-101.

Purushothaman, K., D. Lau., J.M. Saju., D.P. Lunny, S. Vi and L. Orbán, 2016. Morphohistological characterization of the alimentary canal of an important food fish, Asian seabass (Latescalcarifer). J. Life Environ. Sci.4(8): e2377. DOI: 10.7717/peers.2377.

Rahman, M.M., 2004. A qualitative and quantitative study of plankton in relation to some water quality parameters in two beels. M.Sc. Thesis, Department of Aquaculture, Bangladesh Agricultural University, Mymensingh. 119 p.

Rahman, M.R., M.A. Rahman, M.N. Khan and M.G. Hussain, 2004. Observation on the embryonic and larval development of silurid catfish, Gulshan (Mystuscavasius Ham.). Pakistan J. Biol. Sci.,7: 1070-1075.

Santhosh, B. and N.P. Singh, 2007. Guidelines for water quality management for fish culture in Tripura, ICAR Research Complex for NEH Region, Tripura Center, Publication No. 29.

UNFAO, 2010. Press release, 14 September, UNFAO, Rome.

Verschuere L., G. Rombaut, P. Sorgeloos and W. Verstraete, 2000. Probiotic bacteria as biological control agents in aquaculture. Microbiol. Molec. Biol. Rev.,64: 655-671.

Zhou, Q. C., J.A. Buentello and D.M.Gatlin, 2010. Effects of dietary prebiotics on growth performance, immune response and intestinal morphology of red drum (Sciaenopso cellatus). Aquaculture, 309: 253-257.

(Manuscript received 2 September 2020) 